negative, push the needle through the dura and aspirate again. In this way one can differentiate between the cases which need operation and those which do not. There is nothing more disappointing than to open a patient's skull for symptoms and find no marked increase of pressure and realize that you have to deal with a case of multiple hemorrhages in which operation would have been better avoided.

Dr. C. A. Evans, Milwaukee, Wis.: It is apparent that this operation has not met with general acceptance. In order to determine whether or not it is worthy of acceptance I believe it is worth while to report the results obtained. I have operated on twenty-five cases by this method. Most of these were cases of basal fracture, in which the injury itself did not afford sufficient relief from pressure, and lumbar puncture showed bloody fluid. There was a mortality of 20 per cent. Taking the average mortality following such injuries without operation as 50 per cent., this is a reduction in mortality of 30 per cent., approximately what Cushing claims for the operation. The saving of life, however, is not the only consideration, for we must guard against the remote possibilities of the injury. In skull injuries with compound or depressed fractures or when a piece of bone has been removed either by the injury itself or by operation, there is less chance of subsequent trouble than there is in the so-called closed skull fractures. If this is true then surely an opening beneath the temporal muscle, over a mute area of the brain, should lessen the danger of cerebral complications. In two of the cases there was an extradural hemorrhage, and this approach permitted the ligation of the main trunk of the middle meningeal artery and the removal of the clot. I believe that this is the approach of choice in middle meningeal hemorrhage. In two of the cases a primary bilateral drainage was done. Three showed no improvement after unilateral drainage and a later drainage was done on the opposite side with recovery. I do not believe a decompression alone is sufficient. The brain should be elevated and a drain placed in the middle fossa. The whole question of intracranial injuries is one of intracranial pressure. The operation is not one for the open treatment of skull fractures but for the open treatment of intracranial pressure. It matters not what this pressure is due to or whether or not there is a fracture. The important thing is the amount of the pressure and the ability of the brain to withstand it. Trauma to the brain, like trauma to any other part of the body, is followed by the processes of reaction, which is a space-restricting process. Subtemporal drainage relieves this space restriction, absorption takes place, and the circulation is given its best chance to return to normal. There is a large percentage of intracranial injuries that are primarily fatal and the mortality cannot be reduced. Some patients will recover whether operated on or not, either because of the non-severity of the injury, or because of relief -from pressure afforded by the injury itself or by lumbar puncture repeated as needed; a large percentage will recover only after a basal drainage, some after unilateral, others only after bilateral drainage.

Dr. C. E. Ruth, Des Moines, Iowa: In 1889 I reported a case of injury to the skull in which a clot formed beneath the dura and the skull in a child who fell 15 feet and struck on its head on a plank sidewalk. He was trephined and the clot beneath the dura and one beneath the skull and external to the dura were found. The child recovered, and in reporting the case $I$ said we can expect this to occur only in young children in whom the elasticity of the skull is such that after having been driven against the soft brain it will spring away and tear the branches of the middle meningeal artery loose. Immediately after this Dr. J. McFadden Gaston of Atlanta, Ga., wrote me that he had a case in a man aged 56, the symptoms disappearing under purgation, without operation, and the patient died from disturbances of a large clot that formed in the middle fossa extending from the base to the vertex, disproving my theory with regard to the liability of fracture. In another case which occurred in my experience, which was immediately fatal, a clot as large as my hand extended from the base to the vertex of the skull over nearly the entire skull on one side with absolutely no sign of checking of the skull showing at any point. I wish simply to emphasize the importance of what Dr. Blair has said in his paper with reference to the possibilities of relief from the use of the decompression operation. I take exception to decompression without opening the dura. I can conceive of no such thing being possible except it be in a case in which the blood is extradural. To do a decompression operation it is imperative that we open the dura.

Dr. Vilray P. Blair, St. Louis: Dr. Elsberg did not mean to make that statement about not opening the dura. These operative cases were of the most severe type. In almost all of them that was determined by lumbar puncture and by getting free hemorrhage along with the symptoms. Further than this, we became convinced that the chance of saving patients decreased with every hour that the operation was put off. Finally, I believe when one has a brain injury without gross hemorrhage the patient may possibly be helped by a decompression, thus giving a freer circulation.

\section{THE TREATMENT OF TABETIC OPTIC ATROPHY WITH INTRASPINAL INJECTIONS OF SALVAR- SANIZED SERUM}

\author{
A PRELIMINARY REPORT
}

GEORGE T. JOHNSON, M.D., L. Z. BREAKS, M.D. AND

AUGUST F. KNOEFEL, M.D.

TERRE HAUTE, IND.

While one would expect salvarsanized serum to exert about the same influence on the optic atrophy as on the spinal involvement in tabes dorsalis, we deem the observations made in two cases of tabes with optic atrophy treated by intraspinal injections of salvarsanized serum to be of sufficient interest to warrant reporting them. One was a well-marked case of tabes with optic atrophy; the other showed little outside of the ocular findings.

The technic of Swift and Ellis was followed, as described by Hough ${ }^{1}$ and McCaskey. ${ }^{2}$ At first the blood was allowed to stand over night to separate the serum, but later separation was effected by centrifugalization and the whole operation completed at one time. The neosalvarsan was dissolved in about 10 c.c. of resterilized freshly distilled water in a glass syringe, and the blood was aspirated under $40 \mathrm{~mm}$. negative pressure into a 2-ounce skimmed milk bottle of a Babcock tester, so that there was comparatively little exposure of either to the air. All injections were made in the office.

CASE 1.-W. T. C., man, aged 35, married, no children, lineman, with negative family history, had measles when 7 years old, and eruption without sore throat ten years ago, diagnosed as measles. He knows of no chancre. Vision has been gradually failing during the past year. There are no other symptoms. General health is good.

Ocular examination, Jan. 13, 1914, revealed right vision $20 \%$, left vision $2 \% 200$. Tension is normal. Pupils show marked myosis, and react to light but very slightly. Visual field: Right shows slight concentric contraction. Left also shows defect involving upper nasal quadrant. Color sense has depreciated to such an extent that the patient does not distinguish colors in any portion of field. Fundus shows nerve heads grayish-white with sharp-cut margins. Fundus otherwise normal in appearance.

1. Hough, William H.: Intraspinous Injection of Salvarsanized Gerum in the Treatment of Syphilis of the Nervous System, Including Tabes and Paresis, The Journal A. M. A., Jan. 17, 1914, p. 183.

2. McCaskey G. W.: The Autoserosalvarsan Treatment of Syphilis of the Central Nervous System, The Journal A. M. A., Jan. 17, 1914, 
General examination, Jan. 14, 1914, is negative except for absence of left knee-jerk. There is no anesthesia or incoordination. Wassermann reaction is positive. During the period in which patient was under treatment he was seen frequently and the visual fields were charted many times.

Jan. 23, 1914, 0.9 gnu. neosalvarsan intravenously. No reaction. January 24,30 c.c. 40 per cent. serum in normal salt solution intraspinally. Very little reaction. February $10,0.9 \mathrm{gm}$. neosalvarsan intravenously. No reaction. Serum unsatisfactory. February $17,0.9 \mathrm{gm}$. neosalvarsan intravenously. No reaction. February 18, spinal injection of 30 c.c. 40 per cent. serum. Little reaction. Subjective improvement in vision. March $14,0.9 \mathrm{gm}$. neosalvarsan intravenously. March 15,30 c.c. 40 per cent. serum intraspinally. March 27, intravenous injection of $0.9 \mathrm{gm}$. neosalvarsan. March 28, spinal injection of 30 c.c. 40 per cent. serum. April 4, 0.9 gin. neosalvarsan and 30 c.c. 40 per cent. serum. In this case no reactions of any kind followed the intravenous injections of neosalvarsan, and very slight reactions followed the intraspinal injections of serum. These consisted of some pain in head and back of neck. Txamination following last treatment showed a slight left knee-jerk. April 24 , it was found that while visual acuity, as shown by ability to read test letters, had improved but little, the sector defect in left field had disappeared and patient was beginning to distinguish colors. May 24, vision is : right $20 \% 0$; left $20 \%$ Color fields were mapped with $1.5 \mathrm{~cm}$. test object.

CASE 2.-R. W. L., man, aged 37, single, machinist, with negative family history, thirteen years ago had some skin trouble with possible chancre. Patient does not know what diagnosis was made. History otherwise was negative up to two years ago, when vision of right eye began to fail. Vision of left eye began to fail a few months later. For several months right eye has been totally blind. Sight of left has constantly grown worse. Patient had lancinating pains about six months ago.

Ocular examination, February, 1914, revealed right amaurosis. No light perception present. Left vision 20\%00. Entire upper half of visual field wanting. Pupils slightly dilated, right does not react to light directly but consensual reaction is present; left reacts to light very slightly. Patient cannot distinguish colors.

General examination, March 2, 1914, revealed absence of knee-jerks, presence of Romberg sign and marked incoordination of loth upper and lower extremities.

March 3, 1914, $0.9 \mathrm{gm}$. neosalvarsan intravenously. Serum obtained was unsatisfactory. March 10 , neosalvarsan $0.9 \mathrm{gm}$. intravenously. March 11, 30 c.c. of 40 per cent. scrum in normal salt solution intraspinally. Quite severe pain in head and back lasting several days. Subjective improvement in vision followed subsidence of reaction. March 24, neosalvarsan, $0.9 \mathrm{gm}$. intravenously, some leakage occurring outside of vein. March 25, 30 c.c. of 40 per cent. serum intraspinally. Infiltration of right arm at site of injection. April 7, neosalvarsan, $0.9 \mathrm{gm}$. Ulceration present at site of previous injection on right arm. April 8, 20 c.c. of 40 per cent. serum intraspinally. April 21, patient's visual field was practically the same as when first examined but vision had improved markedly. He read $20 / 40 ; 0.9 \mathrm{gm}$. neosalvarsan intravenously and 30 c.c. of 40 per cent. serum intraspinally. Quite a severe reaction followed with pain in back, legs and chest. Right arm improved. April 25, subjective vision worse. May 4, subjective vision improved again. Neosalvarsan, 0.9 gm., intravenously and 30 c.c. of 40 per cent. serum intraspinally. Severe reaction followed in a few days. May 18 , arm healed. Examination showed that coordination was noticeably improved. Knee-jerks absent. Practically no reactions followed the intravenous injections in this case May 20, 1914, patient read 2\% easily and guessed several letters at $2 \% 20$. Patient now distinguished color, and color fields were mapped with $1.5 \mathrm{~cm}$, test object.

This case is especially interesting because of the rapidity with which sight was being lost and the marked improvement which took place following the intraspinal injections.

\section{APPENDICEAL INFLATION}

\section{C. WALLER, M.D. \\ LYNDONVILLE, VT.}

This title is open to criticism, but it serves the purpose of introduction to an interesting observation made by myself and assistants at the Brightlook Hospital, St. Johnsbury, Vt.

Nov. 17, 1913, a girl, aged 8 , while at stool was suddenly seized with violent cramps in the abdomen, and in a few moments became unconscious, but rallied soon after; nausea and vomiting followed, relieving her distress. Twenty minutes after this attack, I found her exhibiting exhaustion and pallor. The temperature, 98, was subnormal; the pulse was 100 ; there was slight tenderness in the right quadrant; the bowels were constipated. Her parents informed me that during the past two years attacks similar to this, though not so severe, had occasioned no anxiety, and that the patient had maintained her usual health though she had complained of slight-stomach disturbances more or less during this time. I suspected chronic appendicitis with adhesions, perhaps, involving the ileum to a point of partial obstruction.

Acting on my advice the parents consented to an operation, November 20. At the, operation $I$ proceeded in the usual manner, and on delivery of the appendix the patient, not being fully anesthesized, began straining with considerable energy, and to my surprise the apparently inoffensive and normal appendix began to inflate to a degree near barsting. With a gauze pad near-by I grasped with both hands the ballooning member to prevent what I felt surely to be impending disaster, and held it until the patient became relaxed, when to my further surprise, I found it necessary to exert gentle pressure to deflate the 2 -inch inflation. After removal, I found within the appendix a No. 6 bird shot. No inflammatory changes vere observed adjacent to or within the appendix.

This, to my mind, in an emphatic way accounts for many heretofore puzzling phenomena as observed when on operating we have found so little to account for the intense suffering and apparent seriousness of acute cases of ileocecal colic, the appendix usually containing small concretions or foreign bodies.

That the appendix, under favorable conditions, may become enormously inflated is a fact, as in the case noted above. The shot (a fecal concretion may serve in a like manner) occluded the appendix lumen as a ball-valve, preventing ready deflation and thereby causing intense pain and attending phenomena, all of which were, in this case, under authentic observation.

Enforcing Sanitary Laws.-What is true of laws in general is equally true of sanitary laws. Many so-called sanitary and public health laws now on our statutes are an obstacle to progress in preventive medicine. Many good sanitary laws are not enforced and cannot be enforced because public sentiment is not fully alive to the importance of preventive medicine. The natural result of this apathy is a withholding of proper authority and proper appropriations by means of which laws can be enforced. Hence, laws fail in their purpose. One of the greatest needs in efficient public health work in the United States is a national Department of Health, a great central educational institution for research, for information, for cooperation. There must be a wellorganized national health department in which must center every function of the government in any way touching public health. The aid and cooperation of this department must be available to every citizen, every community and every city and state board of health in all public health problems, even as the aid of a national Department of Agriculture is now available to every farmer and every farming community. -W. F. King, M.D. in Jour. Indiana State Med. Assn. 